\title{
Community Knowledge and Practice on Sanitation, Hygiene and Household Water Utilization in Afabet City, Northern Red Sea Zone of Eritrea: Cross Sectional Study
}

Berhe Tesfai ( $\square$ berhetesfai04@gmail.com )

Ministry of Health Eritrea https://orcid.org/0000-0003-1820-7395

Hagos Milkyas

Ministry of Health Eritrea

Fitsum Kibreab

Ministry of Health Eritrea

Meron Goitom

Ministry of Health Eritrea

Hermon Berhe

Ministry of Health Eritrea

Asrat Amine

Ministry of Health Eritrea

\section{Research}

Keywords: Practice, Sanitation, Hygiene, Prevalence, Diarrhea, Afabet city

Posted Date: June 2nd, 2021

DOI: https://doi.org/10.21203/rs.3.rs-566458/v1

License: (-) (i) This work is licensed under a Creative Commons Attribution 4.0 International License. Read Full License 


\section{Abstract}

Background: Water and sanitation entitles the human right to affordable access and sanitation. The objective of this study was to determine the knowledge and practice on sanitation, hygiene and water utilization and to estimate the prevalence of diarrhea in Afabet city.

Methods: It was a community-based descriptive cross-sectional type of study with a multistage cluster sampling technique. First, 12 clusters were selected from the city and 30 households were nominated from each cluster. Then, a total of 360 individuals were sampled and every family head was interviewed. A structured interviewer administered questionnaire and field observation was used for data collection from December 05-20, 2020. Cross tabulation and association of variables using chi-square test was determined and results were weighted as cluster sampling was used.

Results: A total of 360 respondents were enrolled in the study with females (75.3\%) and Muslin (99.0\%) predominance. About $66.2 \%$ and $66.9 \%$ respondents were satisfied with the amount and quality of water they received respectively. The prevalence of diarrhea in the community in the last six months of 2020 was $13.0 \%$. The investigators practically approved that $90.7 \%$ of the communities revealed functional toilets and feces were observed in only $5.7 \%$ of the living area of the community. The community's comprehensive good knowledge and practice was $99.4 \%$ and $93.0 \%$ respectively. Their comprehensive knowledge and practice showed significant association with age, sex, marital status, level of education, household size and distance to municipality water source $(p<0.001)$. Furthermore, their comprehensive knowledge and practice, prevalence of diarrhea, presence of latrine, distance from their home to municipality water source and hand washing practice were significantly associated with the administrative area of the study participants $(p<0.001)$.

Conclusion: The community had good level of knowledge and practice but the prevalence of diarrhea was relatively high. Latrines were highly utilized but the usage of soap, personal and food hygiene was slightly low. The level of comprehensive practice, prevalence of diarrhea, distance to municipality water source and hand washing practice was associated to the administrative areas. Enhancing environmental sanitation, personal hygiene and provision of adequate and clean water are highly recommended.

\section{Introduction}

According to a World Health Organization (WHO) report, globally 2.3 billion people lack safe water at home and 844 million people do not have basic drinking water supplies [1]. Furthermore, 2.5 million people worldwide do not have access to any type of improved sanitation [2]. Unsafe drinking water, along with poor sanitation and hygiene accounts for nearly $10 \%$ of the total burden of disease worldwide [3]. Safe, reliable and piped-in water is an essential goal, and treating water at the household or other point of consumption provides a means by which vulnerable populations can improve the quality of their own drinking water [4].

For populations without reliable access to safe drinking water, household water treatment (HWT) provides a means of improving water quality and preventing disease [5]. Unless people have adequate knowledge, attitudes and practices in relation to drinking water, sanitation and hygiene, mere access to the services is not sufficient mitigate health problems related to unsafe water and poor sanitation and hygiene. Information on knowledge, attitudes and practices (KAPs) in relation to water safety, sanitation and hygiene in peri-urban areas is essential to prevent water-borne diseases [6]. Many communicable diseases can be effectively managed by improving water, 
sanitation and hygiene (WASH) practices. Waterborne disease prevalence can be reduced through implementing the three key WASH practices. Safe disposal of feces and hand washing with soap at critical times can reduce prevalence of waterborne diseases by $30 \%$ and $40 \%$, respectively [7].

The prevalence of diarrhea in developing countries has encouraged the development of low-cost, behavior-based interventions to interrupt diarrhea-causing pathogen transmission by improving water quality at the point-of-use and by washing hands using soap. Meta-analysis of efficacy studies indicate that household water treatment reduces diarrhea in children $<5$ years of age by $30-40 \%$ and hand washing with soap reduces diarrhea and acute respiratory infections by $31 \%$ and $24 \%$, respectively [8]. In Sub-Saharan Africa, access to safe drinking water in peri-urban areas is inadequate and complicated by the influx of people from rural to urban areas, poverty, and poor sanitation and housing conditions [9].

According to UNICEF-WHO Joint Monitoring Programme data from 2015 , only $16 \%$ of the population in Eritrea has access to basic sanitation facilities and 76\% practice open defecation [10]. In highland areas of Eritrea, many people practice open-air defecation for different reasons [11].

In Eritrea, currently most of the urban population gets clean water and the use of latrine is promising. But, it is mainly different in the rural areas and their distribution differs among the sub zones and also the level of knowledge and practice of the community is not well determined. To the knowledge of the researchers, there are no similar researches done before to identify this problem in the country in general and in the sub zone in particular. Thus, to fill this gap, the objective of this study was to assess the level of knowledge and practice of the community in sanitation, hygiene and water utilization, and also to determine the prevalence of diarrhea in Afabet city, Northern Red Sea Zone of Eritrea.

\section{Methods}

\section{Study design and sampling method}

It was a descriptive cross-sectional community-based type of study. A multistage cluster sampling technique was implemented as a sampling method to select the study households. First, the city was stratified into six strata and from these strata 12 clusters were selected proportional to their size and 30 households were selected from each cluster. Finally, a total of 360 individuals were sampled from the study area and every head of the selected family was interviewed for the questionnaire.

\section{Study population and site}

The study was conducted in Afabet city, Northern Red Sea zone of Eritrea. This zone has a population of 491,657 and Afabet sub zone and Afabet city have a population of 91,813 and 34,676 respectively [12]. All household heads from the selected study area and who were available during the data collection time were included in the study. Household heads that were unable to speak and with no legible respondent and those with mental retardation were excluded from the study.

\section{Sample size determination}

The sample size for this study was calculated based on various aspects including diarrhea prevalence, precision level and confidence interval. The diarrhea prevalence $(p)$ in the community was not known to the researchers; 
hence, it was assumed that $50 \%$ of the households in the community were infected with diarrhea. Besides, the precision level (d) and the confidence level ( $\mathrm{z}$ ) were taken at $6.5 \%$ and $95 \%$ respectively. The initial sample size was obtained using the formula $n_{1}=z^{2 \star} p * q / d^{2}$

Thus, with the assumption of the estimates mentioned above the initial sample size were 228 . Considering $95 \%$ response rate(r), the final sample size $(n)$ was: $n=n 1 / r=228 / 0.95=239$

Considering a design effect of 1.5 the final sample size was 359. The cluster size was determined at 30 individuals and hence $12(359 / 30=11.9 \sim 12)$ clusters were selected. Therefore, a total of 360 individuals were sampled from the study area.

\section{Data collection}

Data were collected from December 05-21, 2020 for an interval of 15 days. A structured interviewer administered questionnaire and field observation were used to collect the data from the participants. The questionnaire had included the socio demographic characteristics of the study participants, questions which used to assess their awareness on general sanitation, hygiene, availability of water and household water treatment options and the prevalence of diarrhea in their community. The questionnaire was partly adopted from knowledge, attitude and practice study on sanitation, hygiene and solid waste management, private toilet survey 2014 in BO City [13] and finally modified and reformed to the context and objectives of this study. During data collection, field observation was done to validate the response of the household member on specific parameters. The presence of latrine, functionality, availability of water source, water cleanness and handling practices were evaluated. Personal and food hygiene of the family was practically assessed during the data collection time by trained investigators.

\section{Data analysis and interpretation}

Data were entered in CSPro 7.3 and transported to SPSS software and descriptive statistics were presented using frequencies and percentages. Chi-square test was implemented to assess the association of the variables to the background of the participants. $P$ value $<0.05$ was considered significant. Weighting of the results was done as cluster sampling design was used.

\section{Operational definitions}

There were 11 knowledge and 8 practice questions. Those who respond correctly to the knowledge question were scored as 1 and for those responded incorrectly were given 0 point. Results were summed and converted to percent. Finally, those who scored less than $70 \%$ in the knowledge questions were considered as having poor knowledge and those who scored higher than $70 \%$ were considered as having good knowledge in sanitation and water treatment options. The same principle was applied to evaluate the level of practice of the participants.

\section{Ethical consideration}

Ethical approval was obtained from the Ministry of Health Research and Ethics Clearance Committee on $21 / 09 / 2020$ and permission was asked from the zonal and local administrators. The confidentiality of the patient's information was kept secured. The head of the family had signed a written informed consent and participants had the right to withdraw from the research at any stage if they thought the questions are confidential. 


\section{Results}

A total of 360 respondents were enrolled in the study and females were predominant respondents (75.3\%). Almost all $(99.0 \%)$ of the respondents were Muslim in religion and Tigre in ethnicity. About $40.8 \%$ of the study participants were illiterate and $25.8 \%$ reached primary level of education. Most households (87.5\%) own latrine and children $(64.2 \%)$ usually collect water from the water source. Most of the study participants were aged between 21 to 40 years' $(58.5 \%)$ and 41 to 60 years (34.1\%).

Majority of the households had one to two children and owns one to two living rooms in their house, and more than half (59.8\%) of the community had a household size of 4 to 7 individuals. As there is no piped tap water to the households, $58.4 \%$ of the households have access to water provided by municipality (public tap) in less than one kilometer away. While, $24.7 \%$ travel a distance of $1-2$ kilometers and $16.9 \%$ travel more than 3 kilometers for water access. (Table 1) 
Table 1

Socio-demographic characteristics of respondents

\begin{tabular}{|c|c|c|}
\hline Categories & Frequency $(\mathrm{N})$ & Percent (\%) \\
\hline \multicolumn{3}{|l|}{ Administrative area } \\
\hline 01 & 62 & 17.2 \\
\hline 02 & 30 & 8.3 \\
\hline 03 & 90 & 25.0 \\
\hline 04 & 88 & 24.4 \\
\hline 05 & 30 & 8.3 \\
\hline 06 & 60 & 16.7 \\
\hline \multicolumn{3}{|l|}{ Sex } \\
\hline Male & 89 & 24.7 \\
\hline Female & 271 & 75.3 \\
\hline \multicolumn{3}{|l|}{ Religion } \\
\hline Muslim & 356 & 99.0 \\
\hline Christian & 4 & 1.0 \\
\hline \multicolumn{3}{|l|}{ Ethnicity } \\
\hline Tigre & 356 & 98.7 \\
\hline Tigrigna & 3 & 0.8 \\
\hline Saho & 1 & 0.5 \\
\hline \multicolumn{3}{|l|}{ Marital status } \\
\hline Married & 354 & 97.9 \\
\hline Single & 6 & 2.1 \\
\hline \multicolumn{3}{|l|}{ Level of education } \\
\hline Illiterate & 149 & 40.8 \\
\hline Primary & 96 & 25.8 \\
\hline Junior & 74 & 21.7 \\
\hline Secondary and above & 41 & 11.7 \\
\hline \multicolumn{3}{|c|}{ Age of respondent (years) } \\
\hline$<21$ & 10 & 3.0 \\
\hline $21-40$ & 212 & 58.5 \\
\hline $41-60$ & 125 & 34.1 \\
\hline
\end{tabular}




\begin{tabular}{|c|c|c|}
\hline Categories & Frequency $(\mathrm{N})$ & Percent (\%) \\
\hline above 60 & 13 & 4.4 \\
\hline \multicolumn{3}{|c|}{ Number of children in house } \\
\hline $1-2$ & 178 & 83.1 \\
\hline 3 and above & 37 & 16.9 \\
\hline \multicolumn{3}{|c|}{ Number of rooms in the house } \\
\hline $1-2$ & 299 & 82. \\
\hline 3 and above & 61 & 17.4 \\
\hline \multicolumn{3}{|l|}{ Household size } \\
\hline $1-3$ & 62 & 17.6 \\
\hline $4-7$ & 214 & 59.8 \\
\hline 8 and above & 84 & 22.6 \\
\hline \multicolumn{3}{|c|}{ House with Tap water } \\
\hline Yes & 1 & 0.3 \\
\hline No & 359 & 99.7 \\
\hline \multicolumn{3}{|c|}{ House with latrine } \\
\hline Yes & 316 & 87.5 \\
\hline No & 44 & 12.5 \\
\hline \multicolumn{3}{|c|}{ Who collects water } \\
\hline Mother & 93 & 26.7 \\
\hline Father & 33 & 9.0 \\
\hline Boys & 94 & 24.9 \\
\hline Girls & 139 & 39.3 \\
\hline \multicolumn{3}{|c|}{ Distance to municipality (km) } \\
\hline$<1 \mathrm{~km}$ & 227 & 58.4 \\
\hline $1-2 \mathrm{~km}$ & 91 & 24.7 \\
\hline $3 \mathrm{~km}$ and above & 42 & 16.9 \\
\hline Total & 360 & 100.0 \\
\hline
\end{tabular}

Knowledge and practice of the community on sanitation, hygiene and water utilization 
The community had good level of knowledge on most of the questions regarding sanitation and hygiene. Almost all respondents (98.5\%) reported that diarrhea can be prevented and $37.5 \%$ answered that water which looked clean by their naked eye was clean and free of bacteria. Majority of them (91.2\%) affirmed that defecation in toilet could help prevent diarrhea and regular hand washing is very important $(99.8 \%)$.

The results showed that $88.3 \%$ of the communities in the city have some form of toilet in their compound. The commonly used types of toilets are direct pit (43.2\%) and pit latrine with slab (41.4\%) and from those who didn't own toilets, $14.2 \%$ would rather use neighbors toilet than openly defecate. One tenth (9.2\%) of the toilets were not functional and the main reason was that construction was not finished. Burying was the common (77.3\%) method of liquid waste disposal in the community. Even though $98.2 \%$ of the study participants were comfortable with their current sanitation situation, $52.8 \%$ had reported constraints to improve their sanitation in the community. Among the commonly mentioned constraints to improve their sanitation were shortage of material (34.1\%), financial constrains (32.1\%) and no space (15.8\%). The study participants reported that the positive aspects of using toilet are improved hygiene (88.6\%) and improved health (84.9\%). Almost all (99.4\%) of the study participants used water for cleansing after defecation and half of them (49.4\%) reported that open defecation had never practiced in their community. (Table: 2 ) 
Table 2

knowledge and Practice of the community on sanitation and hygiene

\begin{tabular}{|c|c|c|}
\hline Responses & Frequency $(\mathrm{N})$ & Percent (\%) \\
\hline \multicolumn{3}{|c|}{ Do you have toilet on the compound } \\
\hline Yes & 319 & 88.3 \\
\hline No & 41 & 11.7 \\
\hline \multicolumn{3}{|c|}{ What kind of toilet do you have? } \\
\hline direct pit & 161 & 43.2 \\
\hline Pit latrine with slab & 139 & 41.4 \\
\hline Ventilated improved toilet & 30 & 7.4 \\
\hline \multicolumn{3}{|c|}{ If you don't own toilet, where do you dispose human waste? } \\
\hline In the field & 16 & 5.2 \\
\hline Use neighbor's toilet & 52 & 14.2 \\
\hline \multicolumn{3}{|c|}{ How do you dispose your liquid waste } \\
\hline Use as compost & 14 & 3.7 \\
\hline Burying & 277 & 77.3 \\
\hline Digging of new pit & 141 & 37.1 \\
\hline \multicolumn{3}{|c|}{ If you don't own toilet, are you willing to build household toilet } \\
\hline Yes & 68 & 19.5 \\
\hline No & 7 & 1.9 \\
\hline \multicolumn{3}{|c|}{ Do you share the toilets with other households } \\
\hline Yes & 48 & 12.8 \\
\hline No & 312 & 87.2 \\
\hline \multicolumn{3}{|c|}{ Are all toilets functional at the moment } \\
\hline Yes, all functional & 317 & 88.9 \\
\hline No functional toilet & 35 & 9.2 \\
\hline \multicolumn{3}{|c|}{ Why are toilets not functional } \\
\hline Construction not finished & 32 & 9.4 \\
\hline Other technical problems & 11 & 3.2 \\
\hline \multicolumn{3}{|c|}{ Are you confortable with your current sanitation situation } \\
\hline Very confortable & 182 & 49.9 \\
\hline Confortable & 169 & 48.2 \\
\hline
\end{tabular}




\begin{tabular}{|c|c|c|}
\hline Responses & Frequency $(\mathrm{N})$ & Percent (\%) \\
\hline Uncomfortable & 8 & 1.8 \\
\hline \multicolumn{3}{|c|}{ Are there constraints to improve your sanitation } \\
\hline Yes & 184 & 52.8 \\
\hline No & 175 & 47.0 \\
\hline \multicolumn{3}{|c|}{ What are the main difficulties for improving sanitation } \\
\hline Financial constraints & 116 & 32.1 \\
\hline No space indoor or outdoor & 56 & 15.8 \\
\hline No material available & 118 & 34.1 \\
\hline No laborers available & 44 & 13.4 \\
\hline No support/assistance & 19 & 6.8 \\
\hline Lack of know-how & 51 & 14.6 \\
\hline \multicolumn{3}{|c|}{ What are the positive aspects of using own toilet } \\
\hline Improved health & 306 & 84.9 \\
\hline More privacy & 275 & 73.7 \\
\hline Improved hygiene & 324 & 88.6 \\
\hline Improved social status & 99 & 27.4 \\
\hline Improved safety & 87 & 24.2 \\
\hline \multicolumn{3}{|c|}{ Where do you and your household members usually defecate when at home } \\
\hline In own toilet & 315 & 87.2 \\
\hline In neighbor's toilet & 36 & 9.5 \\
\hline Open defecation & 5 & 2.1 \\
\hline \multicolumn{3}{|c|}{ What do you use for cleaning after defecation } \\
\hline Water & 358 & 99.4 \\
\hline Toilet paper & 2 & 0.6 \\
\hline \multicolumn{3}{|c|}{ Is open defecation practiced by you or other household members } \\
\hline Often & 15 & 5.6 \\
\hline Sometimes & 52 & 13.8 \\
\hline Seldom & 116 & 31.3 \\
\hline Never & 177 & 49.4 \\
\hline Total & 360 & 100.0 \\
\hline
\end{tabular}




\section{Hand washing, comprehensive knowledge and practice and prevalence of diarrhea}

According to the family heads report, two thirds of the household members wash their hand more than 5 times per day, and $31.9 \%$ wash 1-4 times per day as needed. And overwhelmingly, $91.9 \%$ of them claimed to use water and soap when washing hands. Only $50.9 \%$ of all households washed their hands after defecating, while $71.3 \%$ washed before preparing food, $95.9 \%$ before eating, $87.5 \%$ after eating, $23.0 \%$ after cleaning babies' bottom, $25.7 \%$ after returning from work and $38.1 \%$ after handling waste.

Almost all of the community had a good level of comprehensive knowledge (99.4\%) and comprehensive good practice of $93.0 \%$. only $7.0 \%$ of the study participants had poor practice on sanitation, hygiene and water treatment options. The self-reported prevalence of diarrhea during the last six months in the community was $13 \%$ and $10.1 \%$ in less than five years children. And $5.9 \%$ of respondents reported of diarrheal illness in their household in the past two weeks and mostly (4.4\%) reported single episode of diarrhea. (Table 3 ) 
Table 3

Hand washing, comprehensive knowledge and practice of respondents

\section{Variables}

Frequency (\%)

Percent (\%)

How often do your household members wash their hands

5 times of more a day

241

68.1

$1-4$ times a day

119

31.9

When do your household members wash their hands

Before preparing food

261

71.3

Before eating

348

95.9

After eating

321

87.5

After defecation

188

50.9

After cleaning baby

87

23.0

When returning from work

91

25.7

After handling waste

148

38.1

What do your household members use for hand washing

Water only

25

8.1

Water and soap

335

91.9

Any family suffer from diarrhea in the last 6 months

$\begin{array}{lll}\text { Yes } & 45 & 13.0 \\ \text { No } & 314 & 86.7 \\ \text { Don't know } & 1 & 0.3\end{array}$

If yes, how many people suffered from diarrhea during the last six months

$\begin{array}{lcc}1-2 \text { incidents } & 43 & 12.4 \\ 3-4 \text { incidents } & 2 & 0.6\end{array}$

In the last 2 weeks, how many household members had Diarrhea?

$\begin{array}{lcc}1 & 12 & 4.4 \\ 2 & 2 & 0.8 \\ 3+ & 2 & 0.7\end{array}$

In the last six months, do your household members less than five years had Diarrhea?

$\begin{array}{llr}\text { Yes } & 26 & 10.1 \\ \text { No } & 252 & 89.9\end{array}$

If yes, how many of your household members less than five year's children suffered from diarrhea during the last six months 


\begin{tabular}{|lll|}
\hline Variables & Frequency (\%) & Percent (\%) \\
\hline 1 & 19 & 5.9 \\
\hline 2 & 3 & 0.8 \\
\hline $3+$ & 3 & 0.8 \\
\hline Comprehensive knowledge & & \\
\hline Good knowledge & 358 & 99.4 \\
\hline Poor knowledge & 2 & 0.6 \\
\hline Comprehensive practice & & \\
\hline Good practice & 338 & 93.0 \\
\hline Poor practice & 22 & 7.0 \\
\hline Total & 360 & 100.0 \\
\hline
\end{tabular}

\section{Household water use and treatment practice}

The community's main sources of drinking water are well (61.7\%), truck water supply (18.6\%), and public tap (16.9\%). The households were asked whether they treat the fetched water regularly and three quarters (76.6\%) of the household confirmed that they treat their water at home, and the most common methods used was straining against cloth (48.9\%), boiling (38.6\%) and adding chlorine (31.7\%). The common reasons mentioned for not treating water are lack of knowledge and materials. Sustainability of water access and amount is alarming as $47.1 \%$ households sometimes suffer shortages water for drinking. And still some family members drink unsafe and untreated water $(73.7 \%)$ when either in the field or away from home, and $23.0 \%$ when they are in a hurry.

Two third of the study participants were satisfied with the amount and quality of water they received. The main reasons for dissatisfaction mentioned are bad taste $(11.8 \%)$, water turbidity $(7.7 \%)$ and poor quality $(3.0 \%)$. More than half $(58.0 \%)$ of the households own water storage tank and they cleaned it using water and OMO (detergent) on weekly $(67.6 \%)$ and monthly $(24.1 \%)$ basis. (Table: 4$)$ 
Table 4

Household water use and treatment practice

\begin{tabular}{|c|c|c|}
\hline Variables & Frequency $(\mathrm{N})$ & Percent (\%) \\
\hline \multicolumn{3}{|c|}{ Do you treat your drinking water regularly } \\
\hline Yes & 277 & 76.6 \\
\hline No & 79 & 22.4 \\
\hline Don't know & 4 & 0.9 \\
\hline \multicolumn{3}{|c|}{ Do you have a water storage tank } \\
\hline Yes & 217 & 58.0 \\
\hline No & 143 & 42.0 \\
\hline \multicolumn{3}{|c|}{ Household not get enough water for drinking? } \\
\hline Yes & 164 & 47.1 \\
\hline No & 195 & 52.6 \\
\hline Don't know & 1 & 0.3 \\
\hline \multicolumn{3}{|c|}{ Have you drunk unclean water in your home? } \\
\hline Yes & 30 & 8.1 \\
\hline No & 315 & 88.0 \\
\hline Don't know & 12 & 3.2 \\
\hline \multicolumn{3}{|c|}{ Reasons for not using household water treatment } \\
\hline No knowledge & 30 & 8.7 \\
\hline No material & 24 & 6.3 \\
\hline Don't know & 13 & 4.2 \\
\hline \multicolumn{3}{|c|}{ How satisfied are you with the amount of water you receive? } \\
\hline Satisfied & 235 & 66.2 \\
\hline Neutral & 78 & 20.7 \\
\hline Dissatisfied & 47 & 13.1 \\
\hline \multicolumn{3}{|c|}{ How satisfied are you with the water quality } \\
\hline Satisfied & 243 & 66.9 \\
\hline Acceptable & 78 & 21.6 \\
\hline Dissatisfied & 39 & 11.3 \\
\hline \multicolumn{3}{|c|}{ If dissatisfied or very dissatisfied, reasons } \\
\hline Bad taste & 36 & 11.8 \\
\hline
\end{tabular}




\begin{tabular}{|c|c|c|}
\hline Variables & Frequency $(\mathrm{N})$ & Percent (\%) \\
\hline Poor quality & 12 & 3.0 \\
\hline Water turbidity & 27 & 7.7 \\
\hline \multicolumn{3}{|c|}{ How often do you wash the storage containers used for drinking water? } \\
\hline Daily & 22 & 6.4 \\
\hline Weekly & 250 & 67.6 \\
\hline Monthly & 80 & 24.1 \\
\hline \multicolumn{3}{|c|}{ How do you wash the storage containers used for drinking water? } \\
\hline Water only & 29 & 9.3 \\
\hline Water and Clorox & 11 & 2.9 \\
\hline Water and OMO & 306 & 84.4 \\
\hline \multicolumn{3}{|c|}{ Respondent drank unfiltered water when } \\
\hline In the field & 138 & 38.4 \\
\hline In a hurry to drink & 88 & 23.0 \\
\hline Away from village & 123 & 35.3 \\
\hline \multicolumn{3}{|c|}{ The main sources of drinking water for members of your household } \\
\hline Public tap & 61 & 16.9 \\
\hline Well & 222 & 61.7 \\
\hline Tanker & 84 & 23.3 \\
\hline Others & 103 & 28.6 \\
\hline \multicolumn{3}{|c|}{ How do you treat your drinking water } \\
\hline Strain by cloth & 176 & 48.9 \\
\hline Add Chlorine & 114 & 31.7 \\
\hline Boiling & 139 & 38.6 \\
\hline Others & 21 & 5.9 \\
\hline
\end{tabular}

\section{Practical observation by investigators}

The latrines were checked for functionality during the spot observation by trained investigators and $90.7 \%$ were deemed functional and the latrine pit hole was left open during the observation period in almost all households (99.0\%). During the investigators visit, presence of soap in the toilet was seen in only $22.9 \%$ of the households. The investigators also approved that the mother's hand was clean in $77.3 \%$ and food was covered in $88.2 \%$ during 
their visit. Garbage container (disposal system) was present only in $43.7 \%$ of the households. And, in $5.7 \%$ of households', feces were observed around the household. (Table: 5) 
Table 5

spot observation by investigators

\begin{tabular}{|c|c|c|}
\hline Variables & Frequency $(\mathrm{N})$ & Percent (\%) \\
\hline \multicolumn{3}{|c|}{ presence of latrine } \\
\hline Yes & 322 & 89.1 \\
\hline No & 38 & 10.9 \\
\hline \multicolumn{3}{|c|}{ Location of latrines } \\
\hline Indoor & 195 & 58.4 \\
\hline Outdoor & 144 & 41.6 \\
\hline \multicolumn{3}{|c|}{ Functional toilets } \\
\hline Yes & 320 & 90.7 \\
\hline No & 29 & 9.3 \\
\hline \multicolumn{3}{|l|}{ Pit covered } \\
\hline Yes & 4 & 1.0 \\
\hline No & 337 & 99.0 \\
\hline \multicolumn{3}{|c|}{ Containment system full } \\
\hline Yes & 14 & 4.8 \\
\hline No & 324 & 95.2 \\
\hline \multicolumn{3}{|c|}{ Presence of soap in toilet at time of visit } \\
\hline Yes & 80 & 22.9 \\
\hline No & 261 & 77.1 \\
\hline \multicolumn{3}{|c|}{ Mother's hands are clean } \\
\hline Yes & 285 & 77.3 \\
\hline No & 75 & 22.7 \\
\hline \multicolumn{3}{|c|}{ View food is covered } \\
\hline Yes & 319 & 88.2 \\
\hline No & 40 & 11.8 \\
\hline \multicolumn{3}{|c|}{ Garbage pit present } \\
\hline Yes & 165 & 43.7 \\
\hline No & 195 & 56.3 \\
\hline \multicolumn{3}{|c|}{ Garbage present inside home } \\
\hline Yes & 18 & 5.4 \\
\hline
\end{tabular}




\begin{tabular}{|lcl|}
\hline Variables & Frequency $(\mathbf{N})$ & Percent (\%) \\
\hline No & 342 & 94.6 \\
\hline Feces observed in living area & \\
\hline Yes & 17 & 5.7 \\
\hline No & 343 & 94.3 \\
\hline
\end{tabular}

\section{Association of comprehensive knowledge and practice with their background}

the comprehensive knowledge of the respondents had showed significant association with their age, gender, marital status, level of education, distance to municipality water source and household size $(p<0.001)$.

Participants age, religion, ethnicity, level of education, distance to municipality water source and household size were also significantly associated with their comprehensive practice $(p<0.001)$. Study participants with distance to municipality water source greater than three kilometers were having poor practice on sanitation, hy giene and water use compared to these with one-kilometer distance to the municipality water source $(p<0.001)$. (Table 6$)$ 
Table 6

Association of comprehensive knowledge and practice with their background

\begin{tabular}{|c|c|c|c|c|c|c|}
\hline \multirow[t]{2}{*}{ Variables } & \multicolumn{3}{|c|}{ Comprehensive knowledge } & \multicolumn{3}{|c|}{ Comprehensive practice } \\
\hline & Good N(\%) & Poor N(\%) & $p$ value & Good N (\%) & Poor N(\%) & $P$ value \\
\hline \multicolumn{7}{|l|}{ Age (years) } \\
\hline$<21$ & $10(100.0)$ & $0(0.0)$ & \multirow[t]{4}{*}{$<0.001$} & $9(90.5)$ & $1(9.5)$ & \multirow[t]{4}{*}{$<0.001$} \\
\hline $21-40$ & 212(100.0) & $0(0.0)$ & & $204(96.3)$ & $8(3.7)$ & \\
\hline $41-60$ & 123(98.4) & $2(1.6)$ & & 113(87.9) & $12(12.1)$ & \\
\hline$>=60$ & $13(100.0)$ & $0(0.0)$ & & 12(89.1) & $1(10.9)$ & \\
\hline \multicolumn{7}{|l|}{ Gender } \\
\hline Male & $89(100.0)$ & $0(0.0)$ & \multirow[t]{2}{*}{$<0.001$} & $83(92.6)$ & $6(7.4)$ & \multirow[t]{2}{*}{0.009} \\
\hline Female & 269(99.3) & $2(0.7)$ & & 255(93.1) & 16(6.9) & \\
\hline \multicolumn{7}{|l|}{ Religion } \\
\hline Muslim & $354(99.4)$ & $2(0.6)$ & \multirow[t]{2}{*}{0.014} & $335(93.1)$ & $21(6.9)$ & \multirow[t]{2}{*}{$<0.001$} \\
\hline Christian & $4(100.0)$ & $0(0.0)$ & & $3(80.8)$ & 1(19.2) & \\
\hline \multicolumn{7}{|l|}{ Ethnicity } \\
\hline Tigre & 354(99.4) & $2(0.6)$ & \multirow[t]{3}{*}{0.019} & $334(92.9)$ & $22(7.1)$ & \multirow[t]{3}{*}{$<0.001$} \\
\hline Saho & $1(100.0)$ & $0(0.0)$ & & $1(100.0)$ & $0(0.0)$ & \\
\hline Tigrigna & $3(100.0)$ & $0(0.0)$ & & $3(100.0)$ & $0(0.0)$ & \\
\hline \multicolumn{7}{|c|}{ Marital status } \\
\hline Married & 352(99.4) & $2(0.6)$ & \multirow[t]{2}{*}{$<0.001$} & $332((92.8)$ & $22(7.2)$ & \multirow[t]{2}{*}{$<0.001$} \\
\hline Single & $6(100.0)$ & $0(0.0)$ & & $6(100.0)$ & $0(0.0)$ & \\
\hline \multicolumn{7}{|c|}{ Level of education } \\
\hline Illiterate & 147(98.7) & $2(1.3)$ & \multirow[t]{4}{*}{$<0.001$} & 139(90.8) & $10(9.2)$ & \multirow[t]{4}{*}{$<0.001$} \\
\hline Primary & $96(100.0)$ & $0(0.0)$ & & 88(91.6) & $8(8.4)$ & \\
\hline Junior & $74(100.0)$ & $0(0.0$ & & $71(96.2)$ & $3(3.8)$ & \\
\hline Sec\&above & $41(100.0)$ & $0(0.0)$ & & $40(97.5)$ & $1(2.5)$ & \\
\hline \multicolumn{7}{|c|}{ Distance to municipality water source } \\
\hline$<1 \mathrm{~km}$ & $225(99.1)$ & $2(0.9)$ & \multirow[t]{3}{*}{$<0.001$} & $217(96.0)$ & $10(4.0)$ & \multirow[t]{3}{*}{$<0.001$} \\
\hline $1-2 \mathrm{~km}$ & $91(100.0)$ & $0(0.0)$ & & $86(94.7)$ & $5(5.3)$ & \\
\hline$>=3 \mathrm{~km}$ & $42(100.0)$ & $0(0.0)$ & & $35(80.0)$ & $7(20.0)$ & \\
\hline
\end{tabular}




\begin{tabular}{|lllllll|}
\hline Variables & \multicolumn{2}{l}{ Comprehensive knowledge } & \multicolumn{3}{l|}{ Comprehensive practice } & \\
\cline { 2 - 6 } & Good N(\%) & Poor N(\%) & p value & Good N (\%) & Poor N(\%) & P value \\
\hline 1 & $156(100.0)$ & $0(0.0)$ & $<0.001$ & $145(92.0)$ & $11(8.0)$ & $<0.001$ \\
\hline 2 & $141(98.6)$ & $2(1.4)$ & & $133(91.7)$ & $10(8.3)$ & \\
\hline 3 \& above & $61(100.0)$ & $0(0.0)$ & & $60(98.3)$ & $1(1.7)$ & \\
\hline Household size & & & & & \\
\hline $1-3$ & $62(100.0)$ & $0(0.0)$ & $<0.001$ & $58(92.9)$ & $4(7.1)$ & \\
\hline $4-7$ & $212(99.1)$ & $2(0.9)$ & & $198(91.2)$ & $16(8.8)$ & \\
\hline 8 \& above & $84(100.0)$ & $0(0.0)$ & & $82(97.5)$ & $2(2.5)$ & \\
\hline Total & $358(99.4)$ & $2(0.6)$ & & $338(93.0)$ & $22(7.0)$ & \\
\hline
\end{tabular}

\section{Association of administrative areas to different background of study participants}

Study participants from administrative area of one and three have the highest good practice compared to the other administrative areas and the lowest practice on sanitation and hygiene was reported in administrative area of two, $(p<0.001)$. The highest prevalence of diarrhea in the city was reported in administrative area of three and two respectively $(p<0.001)$. All study participants from administrative area of two where having greater than three kilometer distance from their home to municipality water source $(p<0.001)$. Majority of the respondents in administrative area of four were practicing hand washing of greater than five times a day compared to the other administrative areas $(p<0.001)$. The level comprehensive knowledge, practice, prevalence of diarrhea, house with latrine, distance to municipality water source and hand washing practice of the participants showed significant association the administrative area in the city. (Table: 7) 
Table 7

Association of administrative area to different background of study participants

\section{Administrative area}

\begin{tabular}{|c|c|c|c|c|c|c|c|c|}
\hline Variables & 01 & 02 & 03 & 04 & 05 & 06 & Total & \\
\hline $\mathbf{N}(\%)$ & N (\%) & $\mathrm{N}(\%)$ & $\mathrm{N}(\%)$ & $\mathrm{N}(\%)$ & $\mathrm{N}(\%)$ & N (\%) & $\mathrm{N}(\%)$ & \\
\hline
\end{tabular}

Comprehensive knowledge of respondents

$\begin{array}{lllllllll}\text { Good } & 61(98.4) & 30(100.0) & 90(100.0) & 87(98.9) & 30(100.0) & 60(100.0) & 358(99.4) & \\ \text { Poor } & 1(1.6) & 0(0.0) & 0(0.0) & 1(1.1) & 0(0.0) & 0(0.0) & 2(0.6) & <0.001\end{array}$

Comprehensive practice of respondents

$\begin{array}{lllllllll}\text { Good } & 61(98.4) & 23(76.7) & 88(97.8) & 84(95.5) & 28(93.3) & 54(90.0) & 338(93.9) & \\ \text { Poor } & 1(1.6) & 7(23.3) & 2(2.2) & 4(4.5) & 2(6.7) & 6(10.0) & 22(6.1) & <0.001\end{array}$

Did any member of your household suffer from diarrhea in the last six months

\begin{tabular}{rllllllll} 
Yes & $4(6.5)$ & $5(16.7)$ & $22(24.4)$ & $8(9.1)$ & $2(6.7)$ & $4(6.7)$ & $45(13.0)$ \\
\hline No & $58(93.5)$ & $25(83.3)$ & $68(75.6)$ & $79(89.8)$ & $28(93.3)$ & $56(93.3)$ & $314(86.7)$ & $<0.001$ \\
Don't & $0(0.0)$ & $0(0.0)$ & $0(0.0)$ & $1(1.1)$ & $0(0.0)$ & $0(0.0)$ & $1(0.3)$ \\
know & & & & &
\end{tabular}

House with latrine

$\begin{array}{lllllllll}\text { Yes } & 57(17.1) & 25(13.8) & 78(23.8) & 79(25.9) & 25(8.0) & 52(11.3) & 316(100.0) & <0.001 \\ \text { No } & 5(10.6) & 5(19.4) & 12(25.7) & 9(20.8) & 5(11.3) & 8(12.3) & 44(100.0) & \end{array}$

Distance from your home to municipality water source

\begin{tabular}{lllllllll}
$<1 \mathrm{~km}$ & $54(24.3)$ & $0(0.0)$ & $70(3)$ & $61(30.0)$ & $0(0.0)$ & $42(13.7)$ & $227(100.0)$ \\
\hline $1-2 \mathrm{~km}$ & $8(8.5)$ & $0(0.0)$ & $20(21.6)$ & $26(30.2)$ & $30(34.2)$ & $7(5.4)$ & $91(100.0)$ & $<0.001$ \\
\hline$>=3 \mathrm{~km}$ & $0(0.0)$ & $30(85.8)$ & $0(0.0)$ & $1(1.7)$ & $0(0.0)$ & $11(12.5)$ & $42(100.0)$
\end{tabular}

How often do your household members wash their hands in a day?

\begin{tabular}{llllllll}
$\begin{array}{l}<5 \\
\text { times }\end{array}$ & $32(26.6)$ & $11(16.8)$ & $38(31.3)$ & $1(0.9)$ & $7(6.2)$ & $29(18.1)$ & $118(100.0)$ \\
$\begin{array}{l}>=5 \\
\text { times }\end{array}$ & $30(11.6)$ & $19(13.5)$ & $52(20.4)$ & $87(36.7)$ & $23(9.5)$ & $31(8.4)$ & $242(100.0)<$ \\
\hline
\end{tabular}

\section{Discussion}

Three key hygiene practices of safe disposal of feces, hand washing with soap at critical times, and the treatment and storage of drinking water are the most effective ways of reducing diarrheal disease. The objective of this study was to determine the community awareness and practice on sanitation, hygiene and water use and to estimate the prevalence of diarrhea in the community. 
The study has demonstrated that three quarters of the respondents regularly treat their drinking water and straining against cloth and boiling are the common ones. This result was higher to other studies that an estimated $33 \%$ of the households in these countries report treating their drinking water at home and boiling were the most dominant water treatment method (21\%). [5] Other study also reported that household water treatment was practiced by $34 \%$ [6] and $18.3 \%$ [14] of the respondents and Chlorination was a major (20\%) method of HWT [6]. This higher practice of water treatment could be mainly due to their higher level of knowledge on the methods and on the disease burden compared to the other study groups.

This study showed that the community has high level of good comprehensive knowledge and practice of on sanitation, hygiene and water treatment options. This result was high compared to other studies that the overall mean knowledge of adults in terms of water safety, sanitation and hygiene was $78.1 \%$ [6]. And in another study good knowledge and practice on WASH were observed in $42.2 \%$ and $49.2 \%$ of the respondents, respectively [14]. This high level of knowledge and practice in the city could be mainly due to the continuous input of the Ministry of Health and the Eritrean Government in improving the life standards of the community in general and the proper utilization and usage of latrines and sanitation through the community lead total sanitation programs of increasing awareness and triggering processes.

Based on the trained investigators practical observation of the communities during data collection, most of them had functional toilets and about one tenth use neighbor's toilet if they lack toilet. This result was similar (88.6\%) [6] and higher (71\%) to other studies [15]. This higher utilization of latrines in the community reflects the works done by the environmental health program of Ministry of Health in construction and proper utilization of latrines in the community to end open defecation in the country.

During the spot observation by the investigators, feces were observed in the living area in only $5.7 \%$ of the households. This result was lower to other study from Ethiopia which reported $11.4 \%$ of the households practiced open-field defecation [6]. This lower practice of open defecation in the community reveals their awareness and the increased utilization of latrines that enhances the motive to end open defecation in Eritrea to achieve the sustainable development goals.

This study indicates that about half of households claimed they wash their hands after defecating and most of them use water and soap. Similarly, peri-urban Ethiopian study showed that hand washing after using the toilet was practiced by $67 \%$ of households. And, $48 \%$ wash their hands with soap and water [6]. Despite these results and even though almost all self-reported that regular hand washing is very important, but during practical observation the narrative changes. Mothers' hands were not clean in $22.7 \%$ of them and only $22.9 \%$ of the households had soap at the toilet during the investigators visit, which is better than similar Ethiopian study (14.98\%) [14]. This shows that the practice of hand washing with soap after defecation is questionable. And that actual practice of proper hand washing in the community seems lower to the self-reported practice and could be some of the reasons for the higher prevalence of diarrhea in the households.

This study depicted two third \% of the households wash the water storage containers used for drinking water on weekly basis and majority with water and OMO (detergent). This practice was higher to other study where $46 \%$ of households clean their water tanks [16]. This further mirrors the higher awareness of the community on household water treatment techniques. 
The trained investigators observation was crucial in assessing the gap on maintaining water safety, and personal sanitation and hygiene. And despite the communities' relatively better knowledge about waterborne fecal-oral disease, the results showed discrepancies on actual practice. Absence of garbage container, unclean mother's hand, absence of soap at toilet, uncovered food and feces in the living area were the noted indicators of actual sanitation and hygiene practices in the community. Hence, empowering the community to increase their practice through behavior change and sustaining the current results would be crucial.

Though the majority of participants are satisfied with the quantity and quality of water supplied; bad taste, poor quality and water turbidity were reported as major problem by one-third of them. Therefore, it is essential to introduce household piped water method or the household water treatment options should be enhanced.

The prevalence of diarrhea in the community in the last six months and in children less than five years age was $13 \% \%$ and $10.1 \%$ respectively. This was similar to other study that the two-week prevalence of diarrhea in children under 5 years of age was $13.6 \%$ [6]. And lower to other study that $19.1 \%$ households experience diarrhea symptoms in the last six months [15]. This lower prevalence in diarrhea in the community could be mainly due to that they had higher knowledge on the association between sanitation, hygiene and diarrhea and also higher percent of the community were using water treatment techniques in their house. The introduction of Rota virus vaccine could have also an impact on the lower prevalence of diarrhea in children less than five years in the community.

Based on the results of this research, the administrative area in the city showed significant association with their comprehensive practice, prevalence of diarrhea, distance to municipality water source and hand washing practice. Other studies showed that statistically significant differences were observed on the levels of knowledge and education [6].

\section{Strength and limitation of the study}

The self-reported practices of the respondents were verified by practical observation of the investigators, which increases the validity of the respondents. This research tries to answer all aspects (sanitation, hygiene and water use) which can cause diarrhea to increase the strength of the study. Further studies with larger sample size that includes the urban and rural communities from different zoba's and different ethnicities are necessary to have different responses

The study was no without limitations. It was conducted in one city which the results can't be used to generalize to the whole country. Since there was no similar study conducted before in the country, it was difficult to associate the results with national previous studies.

\section{Conclusions}

The level of knowledge and practice of the community on sanitation, hygiene and household water treatment in Afabet city was very high and the utilization of toilets and household water treatment options was promising. The prevalence of diarrhea in the community was slightly higher and most of them were satisfied with the amount and quality of water they use. Open defecation was rarely used but personal and food hygiene was not such satisfactory in the community. The level comprehensive practice, prevalence of diarrhea, distance to municipality water source and hand washing practice of the participants showed significant association the administrative area in the city. 
To end open defecation and meet the sustainable development goals, further monitoring and community control strategies for those who defecate in the fields and to sustain the high utilization of toilets are highly recommended. Awareness on personal, food and environmental hygiene and hand washing with soap at the critical times are vital and should be addressed to decrease the higher prevalence of diarrhea in the community. Introducing affordable and reliable household water treatment techniques and providing household pipe water are necessary to improve the living standards of the households.

\section{List Of Abbreviations}

WHO - World Health Organization

HWT- household water treatment

KAP- knowledge, attitudes and practices

WASH- water, sanitation and hygiene

CSPro - Census and Survey Processing System

SPSS- Statistical Package for the Social Sciences

\section{Declarations}

\section{Ethical approval and consent to participate}

Ethical approval was obtained from the Ministry of Health Research Ethical and Clearance Review Committee of Eritrea and written informed consent was obtained from the study participants. Personal information of participants was kept secured.

\section{Consent for publication}

All authors have approved the manuscript for publication, but consent was not applicable

\section{Availability of data and materials}

The data sets used and supplementary materials are available and can be requested from the corresponding author if necessary.

\section{Competing of interest}

Authors declare that they didn't have any competing of interest to disclose

\section{Funding}

This research had no any source of fund except for the data collectors in which their expense was covered by the Ministry of Health, Northern Red Sea region

\section{Author's contribution}


The proposal was designed by BT, FK and HM. FK varnished the study design and methodology part. All authors have participated on supervision of the data collectors. FK designed the data entry tool and BT and MG participated on data entry. Data analysis was done by FK and the first draft of the manuscript was written by BT, MG and HB. All authors have contributed by analyzing, interpreting and writing the manuscript. The final form of the manuscript was shaped by BT, HM, HB, FK and MG. Finally, all authors have read and approved the final manuscript.

\section{Acknowledgments}

The researchers acknowledge the data collectors and the study participants for giving their time and we also thanks the Ministry of Health, Northern Red Sea region for their financial support for the data collectors.

\section{References}

1. Progress on Drinking Water, Sanitation and Hygiene: 2017 Update and SDG Baselines. Geneva: World Health Organization (WHO) and the United Nations Children's Fund (UNICEF), 2017. Available from www.who.int/water_sanitation_health/water-quality/en/.

2. Rheinlander T, Konradsen F, Keraita B, Apoya P, Gyapong C. Redefining shared sanitation. Bulletin of the World Health Organization. 2015; 93:509-10.

3. WHO. World Health Report 2005: Make Every Mother and Child Count. Geneva: World Health Organization; 2005.

4. Sophie Boisson, Mbela Kiyombo, Larry Sthreshley, Field Assessment of a Novel Household-Based Water Filtration Device: A Randomised, Placebo-Controlled Trial in the Democratic Republic of Congo. Journal ListPLoS One5(9); 2010 PMC2937016

5. Ghislaine Rosa and Thomas Clasen, Estimating the Scope of Household Water Treatment in Low- and Medium-Income Countries. Am J Trop Med Hyg. 2010 Feb; 82(2): 289-300. doi: 4269/ajtmh.2010.09-0382

6. Bayeh Abera, Wondemagen Mulu, Endalew Yizengaw, Tadess Hailu, Mulugeta Kibret. Water safety, sanitation and hygiene related knowledge, attitudes and practices among household residents in peri-urban areas in Northwest Ethiopia. Ethiop. J. Health Dev. 2018;32 (3)

7. UNICEF, “Annual Results Report 2016: water, sanitation and hygiene,” Tech. Rep., pp. 1-86, UNICEF, New York, NY, USA, 2016.

8. Benjamin Arnold, Byron Arana, Daniel Mäusezahl, Evaluation of a pre-existing, 3-year household water treatment and handwashing intervention in rural Guatemala. Int J Epidemiol. 2009 Dec; 38(6): 16511661.doi: 1093/ije/dyp241

9. Sheuya SA. Improving the health and lives of people living in slums. Annals of the New York Academy of Sciences. 2008; 1136:298-306.

10. BipinJha, UN Volunteer WASH Officer, Eritrea, delivering community-owned water and sanitation solutions in Eritrea with UNICEF, 22 March 2019

11. Eritrean Rural Water Supply \& Environmental Sanitation Program Water Resources Department. focusing on hygiene and environmental sanitation in Eritrea, UNICEF, Eritrea,1996

12. Ministry of Health, Northern Red Sea Zone, Afabet subzone, Afabet Hospital Report, 2020 
13. Harold.L.Tucker. KAP Study on Sanitation, Hygiene and Solid Waste Management in Bo City. private toilet survey 2014 in BO CITY

14. Abera Aregawi Berhe, Abraham Desta Aregay, Alemnesh Araya Abreha et al. "Knowledge, Attitude, and Practices on Water, Sanitation, and Hygiene among Rural Residents in Tigray Region, Northern Ethiopia", Journal of Environmental and Public Health, vol. 2020, Article ID 5460168, 9 pages, 2020. https://doi.org/10.1155/2020/5460168

15. Montoute, M.C. and A. Cashman. 2015. A knowledge, attitudes and practices study on water sanitation and hygiene in Anse La Raye Village, Saint Lucia. Centre for Resource Management and Environmental Studies. The University of the West Indies, Cave Hill Campus, Barbados. CERMES Technical Report No. 78: 121pp.

16. WASH Knowledge, Attitude and Practices (KAP) survey in Za'atari camp, July 2019 